\title{
Influência da Tutoria na Participação dos Alunos em um Fórum de Discussão On-Line
}

\author{
Nathalia Costa Alves ${ }^{1}$, Samira Pirola Santos Mantilla ${ }^{2}$, Luciana Tavares \\ Perdigão ${ }^{3}$, Mara Lúcia Gomes de Campos ${ }^{4}$, Luiz Gustavo Ribeiro Rolando5, \\ Daniel Fábio Salvador 6
}

\footnotetext{
${ }^{1}$ Designer Instrucional e Pesquisadora, Departamento de Mídias Digitais/Fundação Cecierj. Rua da Ajuda, $\mathrm{n}^{\circ} 5,15^{\circ}$ andar, Centro - Rio de Janeiro - RJ - Brasil. nalves@cecierj.edu.br

2 Designer Instrucional e Pesquisadora, Departamento de Mídias Digitais/Fundação Cecierj. Rua da Ajuda, $\mathrm{n}^{\circ} 5,15^{\circ}$ andar, Centro - Rio de Janeiro - RJ - Brasil. Iperdigao@cecierj.edu.br

3 Designer Instrucional e Pesquisadora, Departamento de Mídias Digitais/Fundação Cecierj. Rua da Ajuda, $n^{\circ} 5,15^{\circ}$ andar, Centro - Rio de Janeiro - RJ - Brasil. smantilla@cecierj.edu.br

4 Coordenadora de TAPs e Tutora a distância do curso de Ciências Biológicas, Departamento de Mídias Digitais/Fundação Cecierj. Rua da Ajuda, n5, $15^{\circ}$ andar, Centro - Rio de Janeiro - RJ, Brasil. maracampos@cecierj.edu.br

${ }^{5}$ Doutorando, Instituto Osvaldo Cruz /Fiocruz, Laboratório Avaliação em Ensino e Filosofia das Biociências, Av. Brasil, 4365 - Manguinhos, Rio de Janeiro, Brasil. gustavor@ioc.fiocruz.br

6 Professor e Pesquisador, Departamento de Mídias Digitais/Fundação Cecierj. Rua da Ajuda, $\mathrm{n}^{\circ} 5,5^{\circ}$ andar, Centro - Rio de Janeiro - RJ - Brasil. salvador@cecierj.edu.br
}

\section{Resumo}

O fórum é uma ferramenta de comunicação assíncrona muito utilizada em cursos online, visto que contribui para uma aprendizagem colaborativa entre os participantes. Os objetivos propostos para o fórum podem ser alcançados com a ajuda de um tutor ativo para mediar as discussões. No entanto, seria a ação do tutor, em fóruns de discussão on-line, essencial para estimular a participação dos alunos? O objetivo desta pesquisa foi investigar como esse profissional pode influenciar a participação ativa dos alunos em um fórum de discussão de um curso de formação de tutores on-line. Analisaram-se os relatórios obtidos na plataforma moodle, as postagens e as interações que ocorreram durante a discussão no fórum. O desempenho dos tutores e a participação dos alunos também foram analisados a partir das rubricas de avaliação. Conclui-se que o número de postagem de tutores não teve influência no número médio de participação de alunos, mas sim na adesão de alunos aos fóruns. A quantidade e a qualidade das participações de tutores, portanto, não estão diretamente associadas. A atuação dos tutores não influenciou no número de postagem de alunos, pois a média de postagem de cada aluno correspondeu às três ações solicitadas no enunciado do fórum.

Palavras-chave: Tutoria; Fórum; Interação. 


\title{
Influence of Tutoring in Students' Participation in an Online Discussion Forum
}

\begin{abstract}
The forum is an asynchronous communication tool often used in online courses in order to contribute to a collaborative learning among participants. The proposed objectives of the forum can be reached with the help of an active tutor to mediate the discussions. However, is the action of the tutor in online discussion forums essential to stimulate student participation? The objective of this research was to investigate how the tutor can influence the active participation of the students in a forum discussion on a training course for online tutors. With this objective, we have analyzed the reports obtained in moodle platform, the posts and the interactions that occurred during the discussion in the forum. We have also analyzed the tutor's performance and the student's participation using evaluation rubrics. According to the results, it was found that student's participation was not influenced by the number of the tutor's posts. The quantity and quality of participation of tutors are not directly associated to the number of posts. The average of posts per student was 3, as it was requested in the statement of the forum.
\end{abstract}

Key words: Tutor; Forum; Interaction. 


\section{Introdução}

A educação a distância consiste em uma modalidade caracterizada principalmente pelo intenso uso de tecnologias de informação e comunicação e pela separação física no espaço e/ou no tempo entre alunos e professores. Essa separação, por sua vez, cria lacunas, sobretudo, no que diz respeito à interação entre alunos e professores, motivo pelo qual muitos alunos podem se sentir desestimulados a participar de um curso a distância.

Segundo Moore (2002), a separação entre alunos e professores na educação a distância afeta o processo de ensino-aprendizagem, ocasionando o surgimento de "um espaço psicológico e comunicacional a ser transposto, um espaço de potenciais malentendidos entre as intervenções do instrutor e as do aluno."

No intuito de suprir os prejuízos desse distanciamento, os ambientes criados a partir de ferramentas ou softwares, os chamados ambientes virtuais de aprendizagem (AVA), têm sido amplamente utilizados em cursos a distância oferecidos via internet (Haguenauer et. al., 2009). Todavia, esses ambientes, em geral, são utilizados apenas como repositório de textos ou atividades, sendo subutilizados pelos professores que, muitas vezes, dispensam as ferramentas de interação disponíveis. Almeida (2003) afirma que é frequente a ocorrência de programas de ensino a distância nos quais cabe ao aluno "navegar pelos materiais, realizar as atividades propostas e dar as respostas, muitas vezes isolado, sem contato com o formador ou com os demais participantes do programa." Isso nos levar a refletir sobre a importância de utilizar mais as ferramentas de interação, no intuito de reduzir o sentimento de "isolamento" por parte dos alunos.

Podemos observar que, em uma sala de aula presencial, os alunos estão habituados a participar de discussões, interagindo entre eles, a partir da mediação presencial do professor - são essas discussões que auxiliam o aluno no processo de construção do seu conhecimento. Em AVA, esse tipo de discussão pode também ocorrer pela ferramenta de comunicação assíncrona chamada fórum, uma das mais comuns disponíveis nesses ambientes.

Uma das maneiras que os alunos têm para interagir entre si e com os professores em ambientes de aprendizagem on-line é a utilização dos fóruns de discussão assíncrona. No entanto, a participação dos alunos nesses fóruns nem sempre 
acontece de forma automática, e não existe um consenso sobre o papel ideal dos tutores nos fóruns (Nandiet al. 2012).

Para o uso da ferramenta fórum, o planejamento prévio e a mediação pedagógica - realizada por tutores ou professores - são fundamentais. É preciso também observar quais estratégias devem ser utilizadas e quais tipos de intervenção devem ser feitos pelo mediador, a fim de que as discussões ocorridas sejam proveitosas nesse contexto.

De acordo com Abawajy (2012), os fóruns de discussão on-line são bastante adequados para sistemas de aprendizagem colaborativa. Além disso, pesquisas atuais indicam que, quando efetivamente concebidos, esses fóruns motivam e melhoram a experiência de aprendizagem dos participantes, favorecendo o processo pedagógico.

As dinâmicas dialógicas do fórum, além de reduzir a distância entre aluno e professor, podem trazer novas possibilidades interativas, auxiliando no processo de construção do conhecimento, sob a perspectiva dialógica e colaborativa (Kratochwill; Sampaio, 2006).

Enfim, o objetivo deste estudo é verificar se as ações dos tutores no fórum de discussão do Curso de Tutoria organizado na plataforma moodle/Cederj influenciaram na participação ativa dos alunos.

\section{Metodologia}

Inicialmente, os cursistas foram divididos em oito grupos. Cada um desses grupos tinha um tutor diferente e uma média de 44 alunos. No fórum, foram solicitadas três ações aos alunos: $1^{\text {a }}$ ação - responder "como podemos criar salas de aula virtuais que estimulem o aprendizado dos alunos, principalmente, na educação a distância em uma plataforma como o moodle"; $2^{a}$ ação -"Escolha o comentário de um dos seus colegas para comentar"; $3^{a}$ ação -"Responda, com uma mensagem, à pergunta que será colocada por seu tutor no ponto de virada do fórum". O comando da ação 3 foi: "Postem uma nova mensagem no fórum, citando, pelo menos, duas ações ou características de fóruns para criar uma boa aprendizagem colaborativa." 
Para a análise dos dados, coletaram-se os relatórios de Log gerados na plataforma moodle do curso e construíram-se gráficos de percentual de postagens dos alunos e tutores. Foram também analisadas qualitativamente as ações dos tutores por meio de uma rubrica de avaliação (Tabela 1 ). Com base nesses critérios, foram atribuídas notas aos tutores, variando entre 1 e 3, sendo 1 a menos positiva e 3 a mais positiva. As análises foram baseadas em ações positivas do tutor, por exemplo, se ele postou o feedback em menos de 24 horas, se postou feedbacks individuais, se estimulou a discussão fazendo novas perguntas durante o feedback. Além disso, foram realizadas entrevistas com os tutores do curso.

Se possível: $1^{a}$ coluna, $3^{a}$ pergunta: à maioria

Tabela 1: Rubrica de avaliação.

\begin{tabular}{|c|c|c|c|}
\hline Critérios & 3 & 2 & 1 \\
\hline $\begin{array}{l}\text { O tutor fez a postagem da } \\
\text { ação } 1 \text { no período certo? }\end{array}$ & $\begin{array}{l}\text { O tutor fez a postagem } \\
\text { dentro do prazo. }\end{array}$ & $\begin{array}{l}\text { Otutor fez a postagem } 24 \\
\text { horas após o prazo. }\end{array}$ & $\begin{array}{l}\text { O tutor fez a postagem } \\
\text { mais de } 24 \text { horas após o } \\
\text { prazo. }\end{array}$ \\
\hline $\begin{array}{l}\text { O tutor postou os feedback } \\
\text { para ação } 1 \text { e } 2 \text { ? }\end{array}$ & $\begin{array}{l}\text { O tutor postou a } \\
\text { maioria dos feedback } \\
\text { antes de } 24 \text { horas. }\end{array}$ & $\begin{array}{l}\text { O tutor postou a maioria } \\
\text { dos feedbacks após } 24 \\
\text { horas. }\end{array}$ & $\begin{array}{l}\text { O tutor não postou a } \\
\text { maioria dosfeedbacks. }\end{array}$ \\
\hline $\begin{array}{l}\text { O tutor respondeu a maioria } \\
\text { dos feedbacks de modo } \\
\text { individual? }\end{array}$ & $\begin{array}{l}\text { O tutor respondeu à } \\
\text { maioria dos feedbacks } \\
\text { de forma individual. }\end{array}$ & $\begin{array}{l}\text { O tutor respondeu à } \\
\text { maioria dos feedbacks de } \\
\text { forma coletiva. }\end{array}$ & $\begin{array}{l}\text { O tutor não respondeu } \\
\text { à maioria dos } \\
\text { feedbacks. }\end{array}$ \\
\hline $\begin{array}{l}\text { O tutor postou o ponto de } \\
\text { virada no período certo? }\end{array}$ & $\begin{array}{l}\text { O tutor fez a postagem } \\
\text { dentro do prazo. }\end{array}$ & $\begin{array}{l}\text { O tutor fez a postagem } 24 \\
\text { horas após o prazo. }\end{array}$ & $\begin{array}{l}\text { O tutor fez a postagem } \\
\text { mais de } 24 \text { horas após o } \\
\text { prazo. }\end{array}$ \\
\hline $\begin{array}{l}\text { O tutor forneceu feedback } \\
\text { para ação } 3 \text { ? }\end{array}$ & $\begin{array}{l}\text { O tutor forneceu o } \\
\text { feedback para a ação } 3 \\
\text { antes de } 24 \text { horas para } \\
\text { a maioria dos alunos. }\end{array}$ & $\begin{array}{l}\text { O tutor forneceu o } \\
\text { feedback para a ação } 3 \\
\text { após } 24 \text { horas para a } \\
\text { maioria dos alunos. }\end{array}$ & $\begin{array}{l}\text { O tutor não forneceu o } \\
\text { feedback para a ação } 3 \text {, } \\
\text { para a maioria dos } \\
\text { alunos. }\end{array}$ \\
\hline $\begin{array}{l}\text { Nos feedbacks o tutor } \\
\text { estimulou a continuar a } \\
\text { discussão? }\end{array}$ & $\begin{array}{l}\text { O tutor estimulou a } \\
\text { continuar a discussão } \\
\text { com perguntas para a } \\
\text { maioria dos alunos. }\end{array}$ & $\begin{array}{l}\text { O tutor respondeu à } \\
\text { maioria dos alunos, sem } \\
\text { estimular com perguntas. }\end{array}$ & $\begin{array}{l}\text { O tutor nem respondeu } \\
\text { e nem estimulou a } \\
\text { discussão da maioria } \\
\text { dos alunos. }\end{array}$ \\
\hline $\begin{array}{l}\text { Houve compartilhamento de } \\
\text { arquivos entre tutores e } \\
\text { alunos? }\end{array}$ & $\begin{array}{l}\text { Houve muitos } \\
\text { compartilhamentos de } \\
\text { arquivos entre tutores e } \\
\text { alunos. }\end{array}$ & $\begin{array}{l}\text { Houve poucos } \\
\text { compartilhamentos de } \\
\text { arquivos entre tutores e } \\
\text { alunos. }\end{array}$ & $\begin{array}{l}\text { Não houve } \\
\text { compartilhamentos de } \\
\text { arquivos entre tutores e } \\
\text { alunos. }\end{array}$ \\
\hline
\end{tabular}

Fonte: Elaborado pelos autores

Para avaliar se os alunos atingiram o objetivo do fórum, analisou-se o desempenho deles na ação 3, tanto no grupo que apresentou mais postagens de alunos quanto no grupo que teve menos postagens. Para isso, uma rubrica de 
avaliação dessas postagens foi elaborada após a ação 3 do tutor (Tabela 2). Depois da análise, realizou-se uma análise estatística, utilizando-se GraphPadPrism 5 (GraphPad Software, Inc.). O teste $\mathrm{T}$ de Student não pareado (Unpaired $t$ test) foi utilizado na comparação entre grupos quanto ao desempenho dos cursistas em relação à ação 3 do fórum de discussão.

Tabela 2: Rubricas de avaliação das postagens utilizadas na pesquisa.

\begin{tabular}{lllll}
\hline Critério & \multicolumn{4}{c}{ Rubricas } \\
\cline { 2 - 5 } & $\mathbf{4}$ & $\mathbf{3}$ & $\mathbf{2}$ & \\
Os alunos & Postou mais & Postou duas ações & Postou uma & Não postou \\
atingiram o & de duas ações & ou características & ação ou & nenhuma ação ou \\
objetivo da & ou & de fóruns. & característica de & característica de \\
ação 3? & características & & fóruns. & fóruns. \\
& de fóruns. & & & \\
\hline
\end{tabular}

Posteriormente, realizou-se uma análise qualitativa das postagens dos alunos do grupo, apresentando um maior número delas por meio da classificação em três temas definidos para esta pesquisa (Tabela 3). 
Tabela 3: Classificação das postagens dos alunos do grupo 1 em diferentes temas.

\begin{tabular}{l|l|l}
\hline Tema & \multicolumn{1}{|c}{ Descrição } & $\begin{array}{l}\text { Exemplo (os termos que permitiram a } \\
\text { classificação da postagem no respectivo } \\
\text { tema estão em negrito) }\end{array}$ \\
\hline $\begin{array}{l}\text { 1- Atuação do tutor } \\
\text { no fórum }\end{array}$ & $\begin{array}{l}\text { Postagens } \\
\text { relacionadas com a } \\
\text { importância da } \\
\text { atuação do tutor no } \\
\text { fórum de discussão. }\end{array}$ & $\begin{array}{l}\text { "A interação constante dos próprios } \\
\text { professores e tutores, pois sem eles de } \\
\text { nada adianta termos toda uma estrutura } \\
\text { de ferramentas de ensino a distância, } \\
\text { inclusive trazendo exemplos de como } \\
\text { aplicar os conceitos e práticas da } \\
\text { disciplina no mundo real." }\end{array}$ \\
\hline $\begin{array}{l}\text { 2- Características } \\
\text { da ferramenta fórum }\end{array}$ & $\begin{array}{l}\text { Postagens que } \\
\text { apresentam } \\
\text { características da } \\
\text { ferramenta fórum. }\end{array}$ & $\begin{array}{l}\text { "Acho que o Fórum foi uma ferramenta } \\
\text { criada para ser dinâmica e objetiva." }\end{array}$ \\
$\begin{array}{l}\text { Sugestões de } \\
\text { melhoria da } \\
\text { ferramenta fórum }\end{array}$ & $\begin{array}{l}\text { Postagens que } \\
\text { sugerem a integração } \\
\text { da ferramenta fórum } \\
\text { com outras } \\
\text { tecnologias. }\end{array}$ & $\begin{array}{l}\text { "Seria proveitoso que os fóruns pudessem } \\
\text { ser acessados através de aplicativos ou } \\
\text { grupos pelas redes sociais, facilitando, } \\
\text { assim, o acesso a qualquer tempo e em } \\
\text { qualquer lugar, através de computadores, } \\
\text { laptops, Ipads, telefones celulares etc... } \\
\text { fica a dica! Abços!" }\end{array}$ \\
\hline
\end{tabular}

\section{Resultados da pesquisa e discussão}

Inicialmente, avaliamos o desempenho do tutor. Na figura 1, pode-se observar a quantidade de postagens de cada um dos oito tutores do curso. O tutor do grupo 1 apresentou maior número de postagens enquanto o tutor do grupo 8 realizou apenas duas postagens ao longo do fórum. 


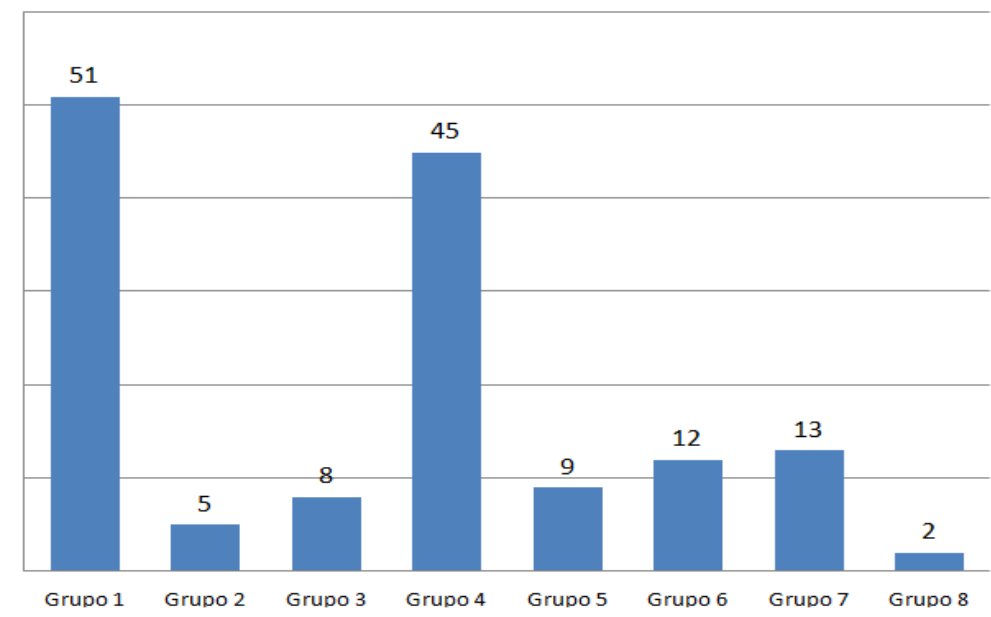

Figura 1. Número de postagens por tutor em cada grupo analisado.

Avaliando a média das ações positivas dos tutores, obtidas por meio das rubricas de avaliação (Figura 2), observou-se que a maioria deles teve boa média de ações positivas - acima de 2 pontos -, com destaque para os tutores 1 e 7 . A quantidade e a qualidade dessa participação, portanto, não estão diretamente associadas.

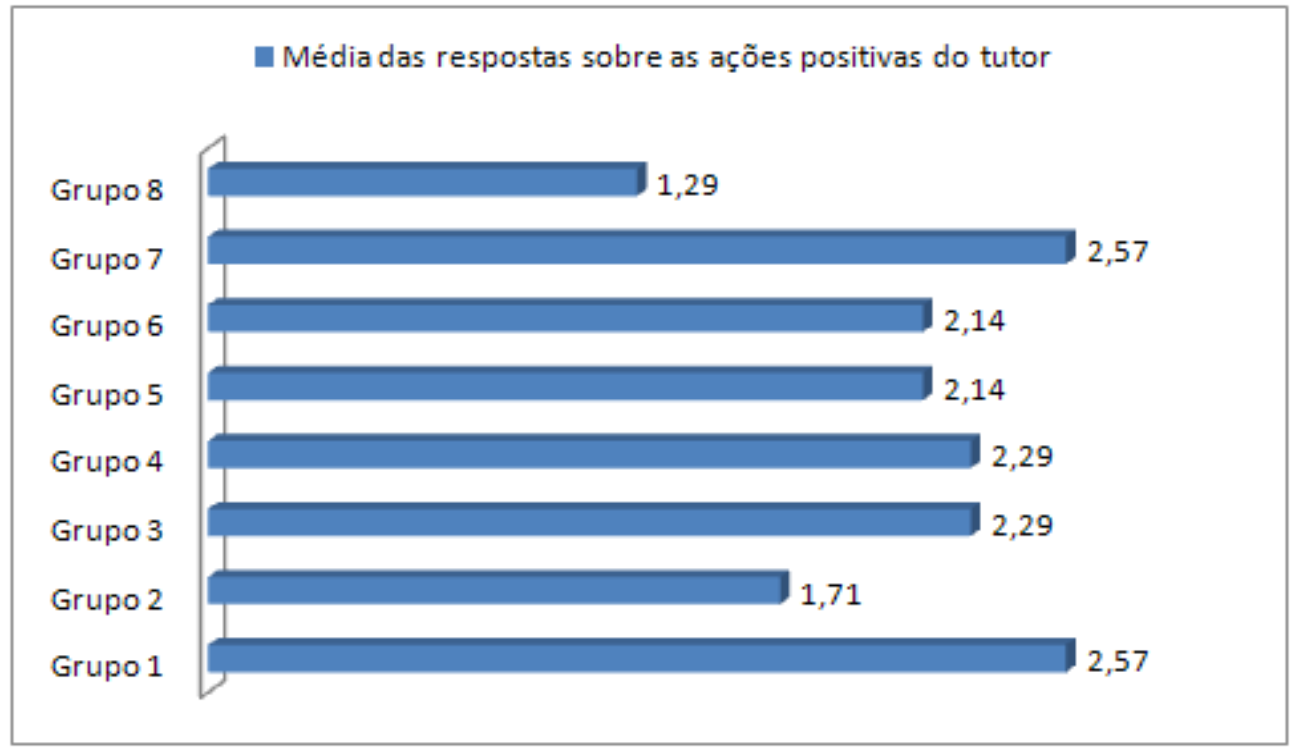

Figura 2. Média de ações positivas dos tutores nos oito grupos analisados.

Analisando a figura 3, verifica-se que a média de postagens por aluno em cada grupo estudado variou em torno de três, o que evidencia que a maioria dos alunos, independentemente da ação do tutor, realizaram três postagens, que correspondem às 
três ações solicitadas no enunciado do fórum. Assim, conclui-se que a atuação dos tutores não influenciou no número de postagem dos alunos.

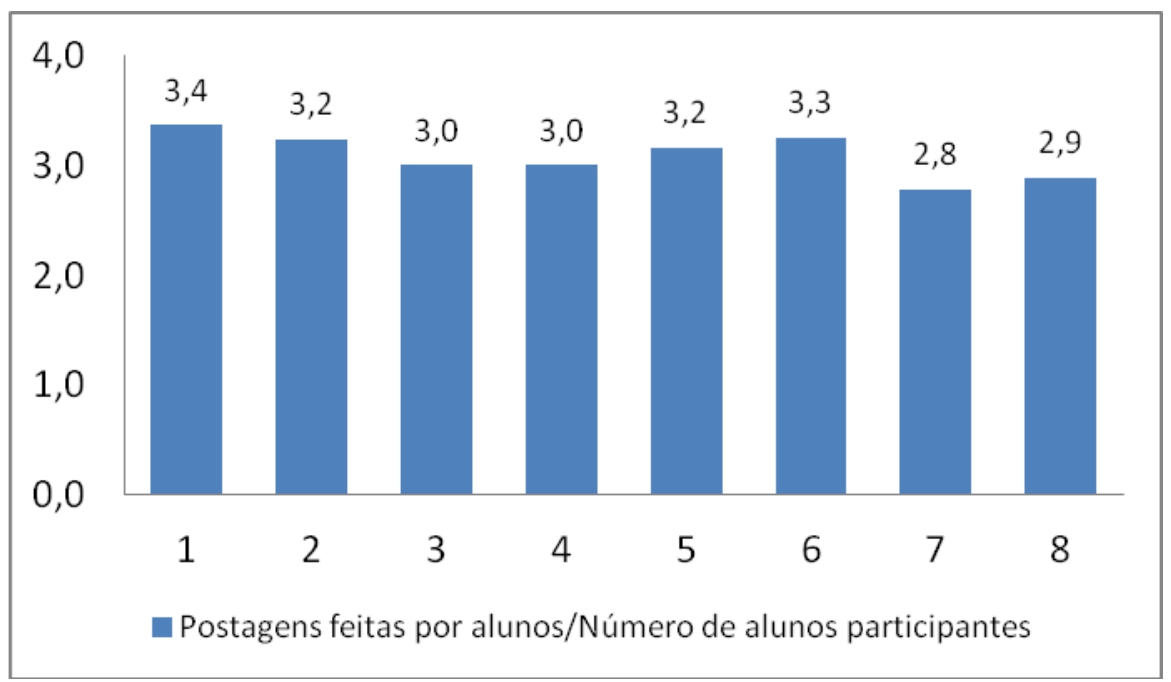

Figura 3. Média de postagens por aluno participante nos oito grupos analisados.

No entanto, a adesão dos alunos à atividade variou bastante entre os diferentes grupos, de maneira que, no grupo 1, que teve maior participação do tutor (Figura 1), a adesão foi maior, enquanto no grupo 2, no qual a participação do tutor foi menor, a adesão foi muito mais baixa (Figura 4 ).

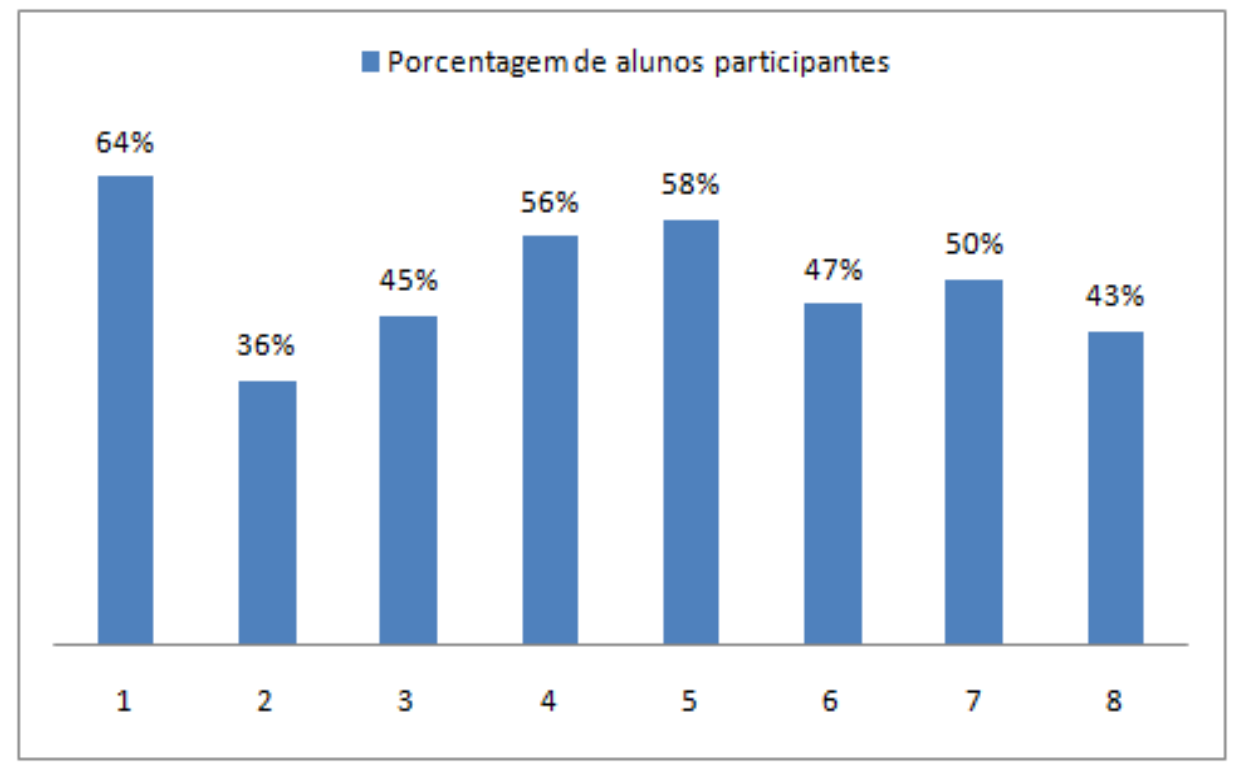

Figura 4. Porcentagem de alunos participantes em cada grupo analisado. 
De acordo com o resultado da pesquisa, o grupo 1 recebeu mais interferência do tutor do que o grupo 8. Como consequência, apresentou um índice maior de interação e postagem, além de uma média maior de ações positivas. Analisando a tabela 4, é possível observar que os alunos do grupo 1 participaram mais do fórum $(63,8 \%)$ se comparados aos do grupo $8(42,8 \%)$. Entretanto, dos alunos que participaram do fórum do grupo $8,83,3 \%$ deles responderam à ação 3, sendo que apenas 53,3\% o fizeram no grupo 1.

Tabela 4.Total de inscritos nos grupos 1 e 8, alunos participantes do fórum e alunos que responderam na ação 3 .

\begin{tabular}{l|l|l|l|l|l}
\hline & $\begin{array}{l}\text { Total de } \\
\text { alunos } \\
\text { inscritos } \\
\text { no } \\
\text { grupo }\end{array}$ & $\begin{array}{l}\text { Total de } \\
\text { alunos } \\
\text { participantes } \\
\text { do fórum }\end{array}$ & $\begin{array}{l}\text { Percentual } \\
\text { de alunos } \\
\text { participantes } \\
\text { do fórum }\end{array}$ & $\begin{array}{l}\text { Total de } \\
\text { alunos que } \\
\text { responderam } \\
\text { na ação 3 do } \\
\text { fórum }\end{array}$ & $\begin{array}{l}\text { Percentual } \\
\text { de alunos } \\
\text { participantes } \\
\text { do fórum } \\
\text { que } \\
\text { responderam } \\
\text { na ação 3 }\end{array}$ \\
\hline $\begin{array}{l}\text { Grupo } \\
\mathbf{1}\end{array}$ & 47 & 30 & $63,8 \%$ & 16 & $53,3 \%$ \\
\hline $\begin{array}{l}\text { Grupo } \\
\mathbf{8}\end{array}$ & 42 & 18 & $42,8 \%$ & 15 & $83,3 \%$ \\
\hline
\end{tabular}

Na figura 6, observa-se o resultado da análise estatística realizada, que indicou não haver diferença entre as médias obtidas pelos grupos 1 e 8 . Assim, conclui-se, neste estudo, que a atuação do tutor não teve influência no desempenho dos alunos na ação 3. Isso pode ter ocorrido pelo fato de o enunciado ter sido bem definido, apresentando três ações específicas para os alunos realizarem ao longo da atividade. 


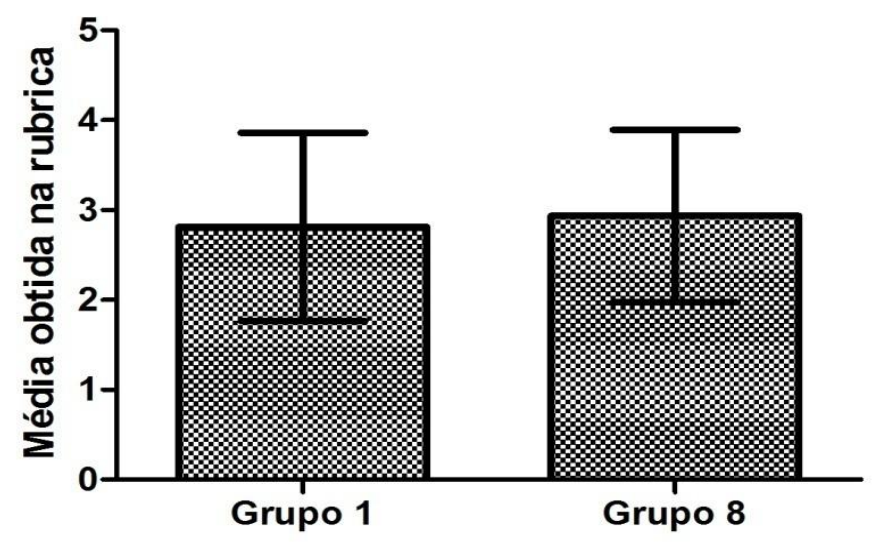

Figura 6. Comparação entre as médias obtidas na rubrica $\mathrm{p}=0,740$ (Unpaired $t$ test).

Em relação à análise qualitativa das postagens dos alunos do grupo 1 , após a ação 3, verificou-se que a maioria delas (63\%) estavam relacionadas com o tema "Características da ferramenta fórum", seguidas por "Sugestões de melhorias da ferramenta fórum" e "Atuação do tutor no fórum" (Gráfico 1). Ou seja, para a maioria dos alunos (futuros tutores), as características da ferramenta fórum são mais importantes para criar uma boa aprendizagem colaborativa do que a própria ação do tutor.

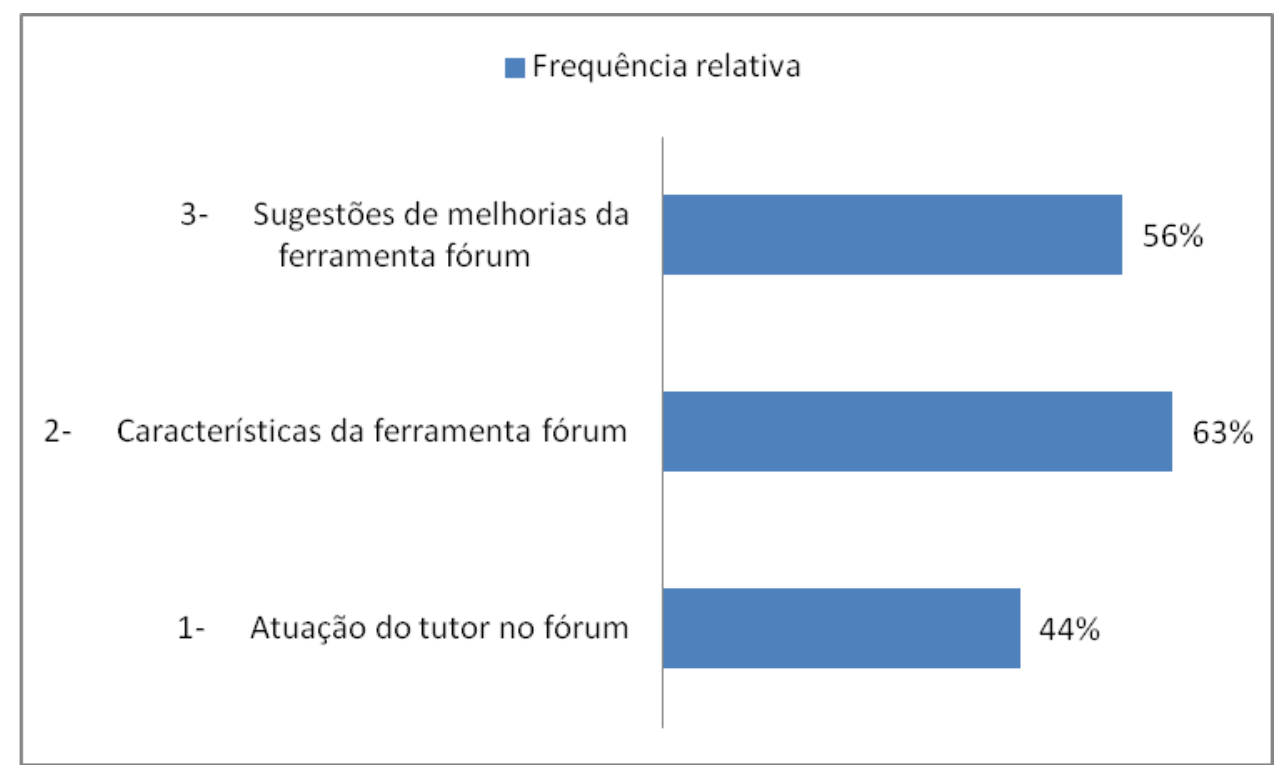

Figura 7. Percentual das postagens classificadas nos três temas. 


\section{Considerações finais}

O número de postagem dos tutores não teve influência no número médio de participação dos alunos, mas sim na adesão desses aos fóruns. Entretanto, à medida que o fórum foi se estendendo, houve uma diminuição do número de participação dos alunos no grupo no qual teve maior número de postagens. A atuação dos tutores não influenciou no número de postagem dos alunos, pois a média dela por aluno correspondeu às três ações solicitadas no enunciado do fórum. Conclui-se então que a atuação do tutor não teve influência no desempenho dos alunos na ação 3, devido à característica peculiar deste fórum, cujo enunciado foi bem definido, contendo três ações específicas para os alunos realizarem ao longo da atividade.

É possível afirmar, no entanto, que esta pesquisa apresentou um ponto negativo, pois as postagens de todos os alunos envolvidos deveriam ter sido analisadas qualitativamente, e não somente as daqueles pertencentes ao grupo que teve maior número de postagens.

Pode-se observar que a avaliação desses aspectos qualitativos é aparentemente mais impactante do que a avaliação dos aspectos quantitativos, no que diz respeito ao entendimento da atuação de tutores em fóruns de discussão on-line e sua importância para os alunos. A avaliação qualitativa das postagens de alunos e tutores é a melhor forma de revelar efetividade na colaboração entre pares e com tutores em fóruns de discussão on-line, visto que dados quantitativos são interessantes apenas para sondagens globais, mas não são suficientes para entender a complexa relação entre ensino e aprendizagem colaborativa que ocorre nesses fóruns.

\section{Referências bibliográficas}

Abawajy,J. Analysis of Asynchronous Online Discussion Forums for Collaborative Learning. International Journal of Education and Learning, v. 1, n. 2, p. , 2012.

Haguenauer, C. J.; MUSSI, M. V.; FILHO, F. C. Ambiente virtuais de aprendizagem: definições e singularidades. Revista Educaonline, vol. 3, n. 2, maio/ago 2009. Disponível

em:

http://www.latec.ufrj.br/revistas/index.php?journal=educaonline\&page $=$ article\&op $=v i$ ew\&path\%5B\%5D=112\&path\%5B\%5D =298 
Kratichwill, S. \& Sampaio, D.R. (2006). As Possibilidades Dialógicas do Fórum de Discussão no Ambiente Virtual de Aprendizagem. Revista Ideação, v. 8, p. 157168.

Moore, M. Three types of interaction. In: American Jornal of Distance Education, v.3, n.2, p. 1-6, $1989 . \quad$ Disponível em: http://www.ajde.com/Contents/vol3 2.htm\#editorial

Moore, M. \& Kearsley, G. O ensino e os papéis do instrutor (capítulo 6). In: Moore, M. \& Kearsley, G. Educação a distância: uma visão integrada. São Paulo, Thompson Learning, 2007 pp. 141-172.

Moore, Michael G. Teoria da Distância Transacional. Revista Brasileira de Aprendizagem Aberta e a Distância, São Paulo, Agosto 2002. Disponível em: http://www.abed.org.br/revistacientifica/Revista PDF Doc/2002 Teoria Distanci a Transacional Michael Moore.pdf

Belloni, M L. Educação a distância. Campinas: Autores Associados, São Paulo, 2001.

Nandi, D.; Hamilton, M.; Harland, J. Evaluating the quality of interaction in asynchronous discussion forums in fully online courses.Distance Education, v. 33, n. 1, p.5-30, 2012.

Schrire, Sarah. Knowledge building in asynchronous discussion groups: going beyond quantitative analysis. Computers \& Education, v. 46 p. 49-70, 2006. 